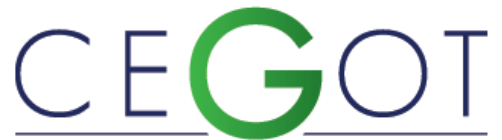

Centro de Estudos de Geografia e Ordenamento do Território
Geografia e Ordenamento do Território, Revista Eletrónica Centro de Estudos de Geografia e Ordenamento do Território http://cegot.org

SOARES, DIEGO

Centro Federal de Educação Tecnológica de Minas Gerais CEFETMG

30.421-169, Av. Amazonas, $n^{\circ}$ 5.253, Belo Horizonte - MG, Brasil dgsoares23@gmail.com

AZEVEDO, RICARDO

Centro Federal de Educação Tecnológica de Minas Gerais CEFETMG

30.421-169, Av. Amazonas, $n^{\circ}$ 5.253, Belo Horizonte - MG, Brasil ricardogeop@yahoo.com.br

NUNES, MALENA

Centro Federal de Educação Tecnológica de Minas Gerais CEFETMG

30.421-169, Av. Amazonas, $n^{\circ}$ 5.253, Belo Horizonte - MG, Brasil malena nunes@yahoo.com.br

\title{
Modelagem da densidade espacial de eventos potencialmente perigosos: uma proposta para análise do risco de deslizamentos de terra no município de Belo Horizonte, Brasil
}

Spatial density modeling of potentially hazardous events: a proposal for landslides risk analysis in the city of Belo Horizonte, Brazil

Referência: Soares, Diego; Azevedo, Ricardo; Nunes, Malena (2019). Modelagem da densidade espacial de eventos potencialmente perigosos: uma proposta para análise do risco de deslizamentos de terra no município de Belo Horizonte, Brasil. Revista de Geografia e Ordenamento do Território (GOT), n. ${ }^{\circ} 16$ (março). Centro de Estudos de Geografia e Ordenamento do Território, p. 345-369, dx.doi.org/10.17127/got/2019.16.015

\section{RESUMO}

A cidade de Belo Horizonte se localiza sobre terrenos de topografia muito irregular e litologia heterogênea. Esse fato, aliado a um planejamento urbano deficitário, favore a ocorrência de deslizamentos de terra. Para melhorar o gerenciamento desse risco, o presente trabalho realizou, junto à Coordenadoria Municipal de Defesa Civil de Belo Horizonte - COMDEC BH ${ }^{1}$, um levantamento das ocorrências de deslizamentos. Os registros permitiram gerar um mapa de densidade espacial do tipo Kernel. Esse mapa foi contraposto aos estudos de Silva et al. (1995) que relatam sobre predisposição a riscos geomorfológicos e conduzem as políticas de habitação municipal. O trabalho permitiu identificar um total de seis regiões de densidade elevada, tendo, todas elas, predisposição também elevada.

Palavras-chave: análise espacial, risco geológico, deslizamentos, mapa de densidade kernel.

\section{ABSTRACT}

The city of Belo Horizonte is located on terrains with very irregular topography and heterogeneous lithology. This fact, together with deficit urban planning, favors the occurrence of landslides. To improve the management of this risk, the present work carried out, together with the Municipal Civil Defense Coordination of Belo Horizonte - COMDEC 
$\mathrm{BH}^{1}$, a survey of the occurrence of landslides. The records allowed to generate a spatial density map of the Kernel type. This map was contrasted with Silva et al. (1995) who report on predisposition to geomorphological risks and conduct municipal housing policies. The study identified six regions of high density, having all of them, also high predisposition.

Keywords: spatial analysis, geological risk, landslides, Kernel density map.

\section{Introdução}

Desastres naturais são fenômenos recorrentes no dia a dia de muitas cidades, causando prejuízos econômicos e perdas de vidas. Segundo o informativo Living with Risks (UN, 2004), em todo o mundo há uma tendência na qual muitos fenômenos ambientais se convertem em desastres. Tal fato é explicado pelo aumento da exposição e da vulnerabilidade da população está submetida. Diversos autores, como Tominaga (2007) e Campos (2011), atribuem esses problemas ao aumento do processo de urbanização, que avança sobre áreas geomorfologicamente inapropriadas à ocupação. Assim, o entendimento e a gestão dos riscos ambientais, de modo geral e não somente os de ordem geomorfológica, devem conceber condicionantes técnicas, de segurança e de sustentabilidade, além dos aspectos políticos, sociais e econômicos.

No Brasil destacam-se desastres hidrometeorológicos, como inundações, e geomorfológicos, como deslizamentos de terra. Esses eventos também se repetem no município de Belo Horizonte, um dos grandes centros urbanos do país. De acordo com Campos (2011) esses eventos ocorrem no município em função de uma vasta diversidade litológica com presença de rochas friáveis e de uma geomorfologia irregular e declivosa. Starling (2015) ainda lembra que sobre esses terrenos se desenvolveu uma grande cidade, de forma tão acelerada, que as políticas públicas não conseguiram englobar estudos de risco. Por conseguinte, considerável parcela da população se tornou exposta às adversidades naturais.

No meio do século XX, segundo Paolucci (2012), os deslizamentos de terra foram responsáveis pela morte de dezenas de pessoas no município. Esses desastres deflagraram programas de redução de riscos que se perpetuam até os dias atuais. Tais programas 
tiveram grande êxito, haja vista que, de acordo com a COMDEC BH, o número de óbitos em função de desastres geomorfológicos, em geral, foi reduzido substancialmente (BELO HORIZONTE, 2007). Além disso, em 2013, o município foi reconhecido pela Organização das Nações Unidas com o prêmio Sasakawa de boas práticas de gestão de riscos ambientais.

Para subsidiar a concepção das políticas públicas de mitigação de riscos, é comum a utilização de ferramentas como mapas temáticos. Essas cartografias se apoiam em atividades voltadas à identificação dos riscos e delimitação das áreas de ocorrência. Em Belo Horizonte os mapas temáticos de Silva et al. (1995) são os mais utilizados no planejamento territorial. Os autores elaboraram um atlas contendo cartas geológicas, geomorfológicas e geodinâmicas. A obra também traz Cartas de Predisposição aos Riscos Geomorfológicos presentes no território. Essas cartografias foram constituídas a partir da compilação das demais cartas elaboradas no trabalho dos autores .

Apesar dos avanços promovidos em relação à gestão de riscos, o município apresenta grandes demandas técnicas nos serviços relacionados à temática. Tal como é observado in loco, uma das grandes demandas é o georreferenciamento dos registros de ocorrências atendidas pela COMDEC BH. Caso houvesse esse incremento, as cartografias de análise de risco poderiam identificar com maior precisão os locais onde mais ocorrem registros de eventos geomorfológicos. Assim, também seria possível planejar, estrategicamente, as intervenções em áreas com grande ocorrência de acidentes dessa ordem.

\section{Objetivos}

Como objetivo geral, este trabalho pretende analisar a distribuição do risco de deslizamentos de terra no território de Belo Horizonte, entre os anos 2012 e 2015. Além disso, os objetivos específicos traçados foram:

- Realizar um levantamento a respeito das condicionantes fisiográficas e urbanísticas que interferem na gestão de riscos geomorfológicos de deslizamentos no município; 
- Espacializar as ocorrências de eventos de deslizamentos registrados pela Coordenadoria de Defesa Civil (COMDEC BH) entre 2012 e 2015, por meio de um mapa de densidade espacial capaz de identificar as áreas de maior predisposição ao risco dessa natureza;

- Verificar possíveis incompatibilidades entre a espacialização gerada e os locais definidos como áreas de risco por Silva et al. (1995).

\section{Referencial teórico}

Estudos prévios sobre avaliação e gestão de riscos podem ser fundamentais no momento de direcionar a aplicação de uma metodologia prática, pois permitem aos investigadores se atentarem para detalhes como terminologias e legislações que, muitas vezes, podem passar despercebidos. São, justamente, esses detalhes que permitem tornar as avaliações de riscos mais consistentes e mais fidedignas em relação aos processos ambientais que se desenvolvem no território. Assim, se faz fundamental o detalhamento de alguns estudos.

\subsection{Conceitos para Avaliação de Riscos}

A literatura sobre riscos ambientais comumente assume uma postura técnica e fundamentada por conceitos muito particulares. Daí a necessidade de, antes de iniciar um novo trabalho nessa área, realizar definições conceituais que permitam estabelecer um padrão ao longo da investigação. Esse procedimento é adotado por muitos autores como UN, 2004; García, 2007; Tominaga, 2007; Abreu, 2007; Campos, 2001; Paolucci, 2012.

De acordo com o informativo técnico Living with Risks, publicado pela Nações Unidas em 2004, "risco" é a probabilidade de consequências prejudiciais, ou danos esperados, resultantes da interação entre processos perigosos naturais, ou induzidos pela ação humana, e as condições de vulnerabilidade (UN, 2004).

Esta definição de risco se assenta em outras duas: Periculosidade e Vulnerabilidade. "Periculosidade" está relacionado à frequência de ocorrência e à intensidade com que tem lugar o fenômeno natural que constitui uma ameaça (GARCÍA, 2007). Contudo, fenômeno 
natural nem sempre gera perigo, já que pode não causar danos. A simples ocorrência de um fenômeno caracteriza um "evento". Quando esse gera danos socioeconômicos é caracterizado como um "acidente", ou "desastre" (CAMPOS, 2011). Quando o acidente gera danos muito elevados, ultrapassando limites pré-estabelecidos nos planos de contingência, que são definidos pelo poder público, é utilizado, comumente, o jargão "catástrofe".

Já "vulnerabilidade", para UN (2004), é o conjunto de condições determinadas por fatores ou processos sociais, econômicos e ambientais que aumentam a exposição de uma comunidade ao impacto negativo de uma ameaça. Condições como pobreza, insegurança e falta de comida, ou de terra, estão associadas a vulnerabilidade, uma vez que reduzem a capacidade de um indivíduo responder a uma situação inesperada.

A vulnerabilidade está diretamente relacionada a possibilidade de um acidente se transformar em uma catástrofe. Isso, visto que, caso o fenômeno ocorra em uma região de fragilidade socioeconômica, podem ser causados danos irreparáveis. Além dos danos diretos (perdas materiais e humanas), também podem surgir danos indiretos como disseminação de epidemias e movimentos migratórios. De acordo com Umbelino (2006) a vulnerabilidade é a capacidade que uma comunidade possui para resistir a um evento adverso, responder adequadamente e conseguir se reconstituir após o término do evento.

Uma comunidade que possui capacidade de resposta e consegue reagir rapidamente a um desastre é uma comunidade "resistente". Já a comunidade que consegue se adaptar à nova situação gerada após esse evento e se restabelece ao que era antes dele é "resiliente". "Resiliência" é, portanto, a capacidade que um sistema, expostos a riscos, possui para se recuperar dos efeitos de um desastre, de forma premeditada e eficiente através da restauração das suas estruturas básicas e funções essenciais (UN, 2010).

Esses conceitos são importantes para a realização de procedimentos de avaliação de riscos, que são metodologias que permitem identificar uma ameaça, caracterizar e estimar sua importância, com a finalidade de definir alternativas de gestão (MPO, 1998). A avaliação de riscos é apenas uma das várias ferramentas que permitem reduzir a vulnerabilidade. 


\subsection{Gestão de Risco de Desastres}

É importante observar que uma situação de emergência requer um planejamento prévio para ações imediatas, de forma a evitar que um evento se torne um desastre. A gestão do desastre deve incluir ações integrativas entre instituições públicas, organizações não governamentais, órgãos privados e comunidades. Cabe ao serviço de Defesa Civil de cada município, ou comarca, fazer a conexão desses arranjos de forma a reduzir as consequências decorrentes dos eventos, ou mesmo evitar que eles aconteçam (FÉLIX, 2016).

Para isso, tal serviço deve elaborar um Gerenciamento de Riscos de Desastres - GRD. Esse é entendido como o processo multidisciplinar que leva ao planejamento, às políticas públicas e às medidas que favorecem a prevenção e o controle dos efeitos de fenômenos adversos sobre as populações, infraestruturas, bens, serviços e meio ambiente (UN, 2010).

Em todo o mundo o GRD se tornou tão importante que diversos governos e instituições desenvolvem complexos sistemas de defesa interna. Essa tendência teve início a partir da década de 1960, no contexto da Guerra Fria. Segundo Félix (2016), nessa época ficou evidente, para as nações, a necessidade de a sociedade estar preparada para agir em situações de ataques inimigos e de emergências com desastres, sejam eles geofísicos, químicos, biológicos ou nucleares. Esses sistemas incluíam mecanismos de detecção de riscos, alerta contra acidentes, abrigos, sistemas logísticos de evacuação, equipes de busca e salvamento, uso de geotecnologias e implementação de legislações e normas que viabilizassem todo o processo (UN, 2010; FEKETE et al., 2015; FÉLIX, 2016).

\subsection{Cartografia e Modelagem para a Análise de Riscos}

A proposta metodológica de análise de riscos desenvolvida aqui se baseia na avaliação do meio físico a partir de geotecnologias. Autores como TOMINAGA (2007), ABREU (2007), OLIVEIRA (2009) e PAOLUCCI (2012) realizaram trabalhos importantes sobre gerenciamento de áreas de risco a partir do uso de técnicas cartográficas. De acordo com eles, as cartas são indispensáveis para avaliações de risco pois, permitem sistematizar diversas informações disponíveis e determinar a possibilidade de que ocorram certos eventos indesejáveis. 
No estudo dos desastres naturais existe uma grande variedade de tipos de cartografias. Em geral, as mais utilizadas na análise de risco se baseiam em informações geofísicas e socioeconômicas do território. Assim, é possível a formulação dos Mapas Temáticos, que trazem a informação espacial básica e incluem diversos temas sobre o meio (ABREU, 2007).

A combinação desses conhecimentos permite a formulação das Cartografias Geoambientais, que, segundo Tominaga (2007), correspondem a um processo de obtenção, análise, representação e comunicação de dados e informações sobre os meios físico, biótico e socioeconômico. Essas cartografias são chamadas de Cartas Geotécnicas quando são desenvolvidas contemplando as propriedades geotécnicas de solos e rochas, além de possibilitar a harmonia entre as diversas formas de uso do solo com os processos geodinâmicos existentes (TOMINAGA, 2007; OLIVEIRA, 2009). Podem ser ainda Cartas de Predisposição quando classificam os terrenos em distintos graus de propensão à ocorrência de processos adversos do meio físico (ABREU, 2007).

De acordo com as Nações Unidas (UN, 2007; UN, 2010), as técnicas e procedimentos adotados para um mapeamento devem ser escolhidas caso a caso, conforme as características de cada local, tipo de ameaça, recursos tecnológicos e financeiros disponíveis e objetivos propostos para o trabalho. Muitas técnicas, são baseadas em Geotecnologias, que, segundo Marcelino (2008), possibilitam a coleta, o armazenamento e a análise da grande quantidade de dados envolvidos nas análises de desastres naturais.

Entre as principais geotecnologias utilizadas para o planejamento territorial e para a elaboração de sistemas GRD estão os Sistemas de Geoposicionamento, os Sistemas de Informações Geográficas - SIG e as técnicas de Sensoriamento Remoto. Ao associar computacionalmente dados cartográficos e alfanuméricos, o Geoprocessamento é capaz de integrar numa única base de dados, informações provenientes de múltiplas fontes, a fim de analisar as interações existentes entre as variáveis, elaborar modelos preditivos e dar suporte às tomadas de decisões (TOMINAGA, 2007; MARCELINO, 2008).

O poderio das tecnologias computacionais para o processamento de dados, em grandes volumes e em tempo curtos, permitiu à cartografia e às ciências ambientais o desenvolvimento do campo da Modelagem Ambiental. Vários autores (MOURA, 2012; FEKETE et al., 2015) afirmam que o modelo não é a realidade, mas apenas uma aproximação 
que a torna mais compreensível ao entendimento humano. Nesse processo, muitas vezes, a Modelagem Ambiental se utiliza de outras ciências como a Computação, a Matemática e a Estatística para caracterizar o espaço e os fenômenos nele incidentes.

Alguns modelos Geoestatísticos são extremamente eficientes para essa tarefa. Alguns deles se baseiam em técnicas de interpolação, que são capazes de estabelecer valores inferidos para um parâmetro vazio em referência a um atributo em análise (MOURA, 2014). Para isso é necessário considerar os atributos dos "espaços" vizinhos, desde que esses atributos sejam parâmetros discretos e conhecidos.

\section{Caracterização do munícipio de Belo Horizonte - MG}

Em todo projeto ou estudo relacionado à gestão territorial é necessário uma caracterização que envolva as peculiaridades ambientais e socioeconômicas da região. No escopo do tema proposto, uma caracterização territorial, pode permitir o entendimento dos riscos de desastres e subsidiar mecanismos estratégicos de prevenção e mitigação de impactos.

\subsection{Caracterização da Litologia}

Belo Horizonte possui uma litologia diversificada, tal como é visto em seu mapeamento geológico (Figura 1). Esse mapeamento foi feito a partir de cartografias à escala de 1:25.000, elaboradas por Silva et al. (1995) e posteriores adaptações de Parizzi et al. (2010). Em tal leitura é possível dizer que no município ocorrem as formações do Complexo Belo Horizonte, do Domínio Metassedimentar e a Sequência Sedimentar (REIS, 2011).

O Domínio do Complexo Belo Horizonte abrange em torno de $70 \%$ do território e agrupa as rochas gnáissicas, parcialmente remobilizadas (REIS, 2011). Estas rochas costumam ocorrer de forma muito saprolitizada, ou recobertas por manto de intemperismo. Fato que, segundo Silva et al. (1995), se torna uma condição muito propícia à erosão.

A Sequência Metassedimentar, de acordo com esses autores, é constituída principalmente por rochas metassedimentares que recobrem cerca de $30 \%$ do território e se distribuem ao 
sul. Também é observado em todos os subgrupos a ocorrências de tipos variados de filitos, que são rochas resultantes de processos de metamorfização, com granulação fina e foliação acentuada. Características que conferem grande erodibilidade ao embasamento geológico.

Por fim, as Formações Superficiais são, geralmente, depósitos do cenozoico que recobrem parcialmente as litologias do Complexo Belo Horizonte. Ocorrem em grandes variedades conforme sua origem, textura, composição e laterização. De acordo com Campos (2011), destacam-se os sedimentos aluviais, canga, depósitos de vertentes e depósitos dos fluxos de detritos de natureza torrencial.

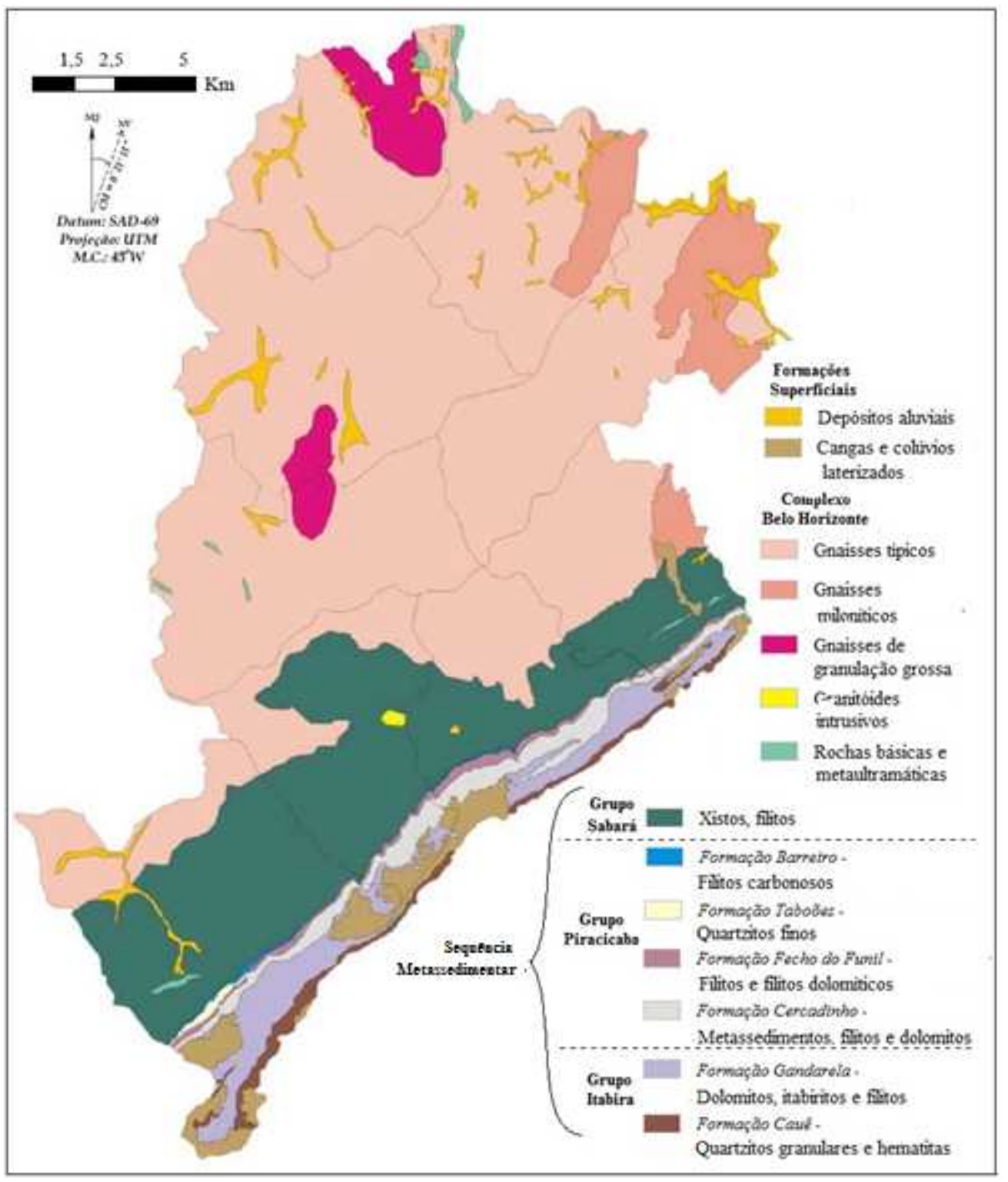

Figura 1 - Carta Geológica de Belo Horizonte Fonte: Silva et al. (1995) e Parizzi et al. (2010) 


\subsection{Caracterização da Geomorfologia}

Silva et al. (1995) demonstraram que o território em análise possui uma fisiografia diversificada e vinculada às propriedades geológicas de seu substrato. Os fatores geológicos condicionaram o desenvolvimento de duas unidades geomorfológicas: o Maciço do Quadrilátero Ferrífero e a Depressão de Belo Horizonte.

A porção do extremo sul de Belo Horizonte está inserida no Maciço do Quadrilátero Ferrífero. Esse compartimento corresponde a uma fisiografia serrana com as atitudes que superam os 1.100 metros acima do nível do mar (BELO HORIZONTE, 2007). Nesse território se desenvolveu uma forma emblemática: a Serra do Curral, que possui camadas de Itabirito protegidas da erosão por couraças ferruginosas conhecidas como Canga (CAMPOS, 2011).

Ainda segundo Silva et al. (1995) o Compartimento do Quadrilátero Ferrífero exerceu papel fundamental na evolução do relevo de Belo Horizonte, limitando a extensão dos processos erosivos que moldaram a Depressão Belo Horizonte, a norte. Essa bacia sedimentar se estende da base da Serra do Curral, a sudoeste, até as superfícies aplainadas, a norte. Nesse compartimento ocorrem colinas com topos planos e com encostas côncavo-convexas, entre 800 e 900 metros. Essas formações são originadas pela dissecação fluvial das áreas gnáissicas promovida pela rede de drenagem dos rios Velhas e Paraopeba (CAMPOS, 2011).

Outra característica geomorfológica importante é a declividade, que interfere diretamente na velocidade das águas que se acumulam nas ruas, becos e canais. Como aponta Oliveira (2009), se, por um lado, as áreas de baixo relevo são propícias à acumulação da água da chuva, por outro, as encostas acabam submetidas aos movimentos de massa associados à ação da gravidade. Pela análise do mapa de declividades (Figura 2) é observado que as grandes elevações com declives acentuados (> 47\%) estão localizadas com predominância na porção do sudeste do município. 


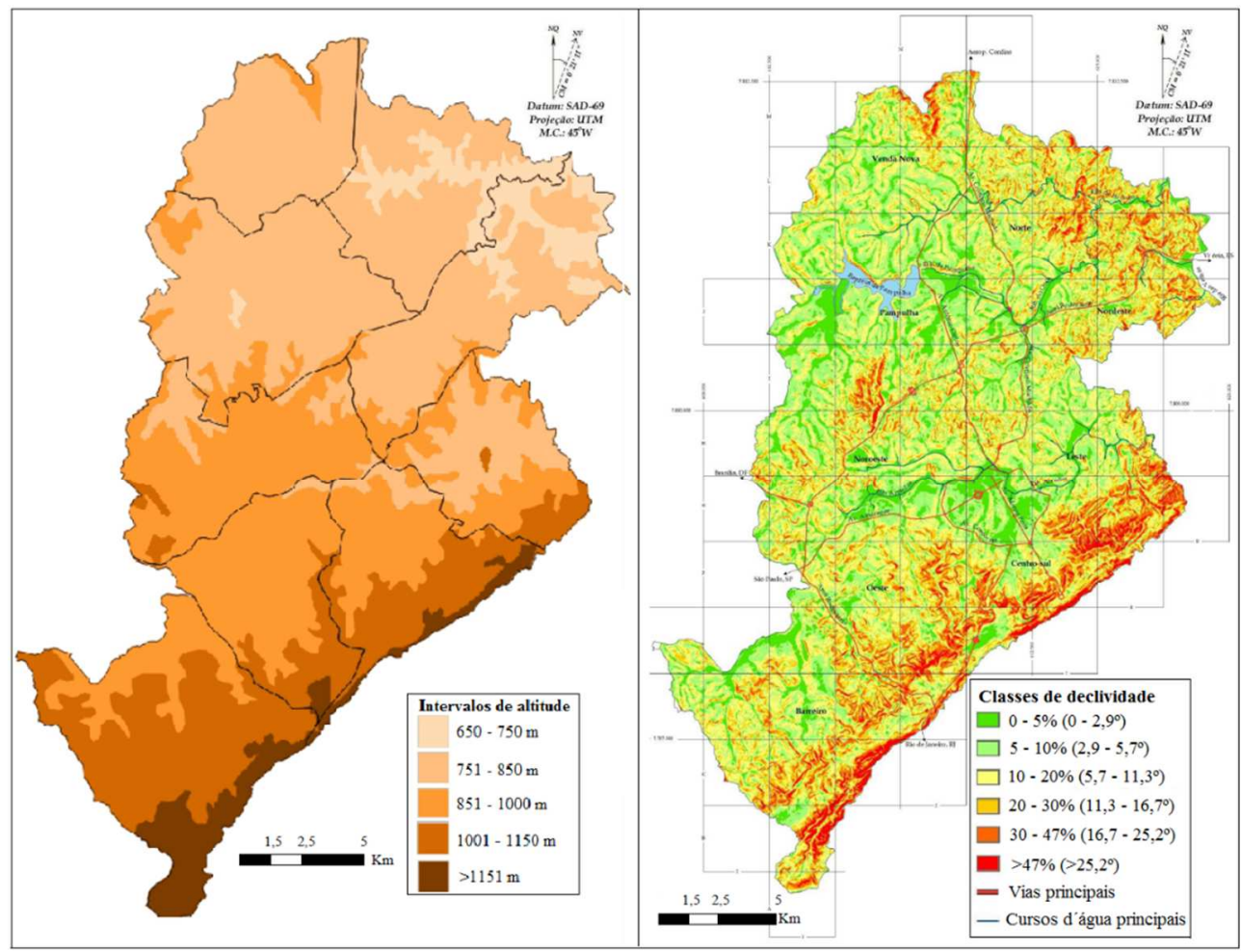

Figura 2 - A) Carta de Altimetria; B) Carta de Declividade de Belo Horizonte Fonte: Oliveira (2009)

\subsection{Caracterização Urbanística}

Como afirma Nogueira (2002), estudar o comportamento da urbanização além de permitir compreender a instauração e o desenvolvimento dos riscos ambientais nas cidades, também permite pensar em estratégias de prevenção, formas de mitigação dos impactos decorridos e ações para aumentar a resiliência e reduzir a vulnerabilidade da população.

Em Belo Horizonte a intensificação dos riscos ambientais é um processo histórico que se inicia junto com o município, ainda no século XIX. O plano urbano adotado para a construção primou por um sistema viário retilíneo e baseado nas influências haussmanianas ao invés de seguir a topografia, respeitar as curvas de nível e as áreas de várzea (PAOLUCCI, 2012). Com as mudanças políticas e econômicas vivenciadas pelo Brasil, durante o século XX, a capital mineira, então projetada para 200 mil habitantes, ultrapassou a marca dos 2,5 milhões no século XXI (CAMPOS, 2011). Nesse processo, o poder público não conseguiu acompanhar a urbanização, estabelecendo normas urbanísticas e realizando a devida fiscalização. Assim, surgiram ocupações em áreas de instabilidade geomorfológica, sendo algumas delas de caráter irregular (PAOLUCCI, 2012; STARLING, 2015). 
Apesar dos riscos ambientais serem mais complexos nos assentamentos precários, eles também ocorrem em regiões nobres. Movimentos de massa ocorrem tanto em áreas de baixo padrão construtivo quanto em áreas de alto padrão (PARIZZI et al., 2010). Nas últimas décadas, várias foram as catástrofes em localidades urbanisticamente regulares e que atendem às normas, tal como ocorreu nas regiões dos bairros Estoril e Buritis.

Durante as décadas de 1990 e 2000 novas diretrizes urbanísticas nacionais, impostas pela Constituição Federal de 1988 e pelo Estatuto das Cidades, além da necessidade iminente de reduzir as desigualdades espaciais, forçaram o poder público municipal a buscar a democratização dos espaços urbanos e a consonância da urbanização com as condicionantes ambientais. Nessa lógica também foi deflagrado um processo de substancial redução dos riscos ambientais e aumento da resiliência (PAOLUCCI, 2012; STARLING, 2015).

Surgiram, então algumas iniciativas jurídicas como:

- $\quad$ Plano Diretor Municipal (Lei $\left.n^{\circ} 7.165 / 1996\right)$, instrumento capaz de conciliar os interesses das iniciativas pública, privada e da população, aspectos sociais, econômicos e ambientais em uma estratégia de desenvolvimento.

- $\quad$ Lei de Planejamento, Uso e Ocupação do Solo - LPOUS (Lei no 7.166/1996), capaz de reorganizar o espaço e instrumentalizar de gestão e planejamento por meio de um zoneamento e imposição de diretrizes elaboradas para cada zona.

Apesar da efetivação das leis, a gestão urbana ainda é um desafio, pois as pessoas encontram várias maneiras de as contornar e fugir de possíveis taxas e sansões. O que é muito facilitado por uma fiscalização deficitária que não consegue verificar todas as modificações posteriores às obras (PAOLUCCI, 2012).

\section{Metodologia}

Após a revisão da literatura pertinente, foi elaborada uma metodologia de trabalho, dividida em quatro etapas sequenciais, tal como é demonstrado pela Figura 3. 


\section{ETAPA}

1. Aquisição de dados junto a Coordenadoria de Defesa Civil;

2. Triagem e separação dos dados relevantes; 2a ETAPA

1. Georreferenciamento dos eventos ocorridos entre 2012 e 2015;

Interpolação dos dados

2. Reclassificação

3. Vetorização (shp.) das matrizes (tif.) geradas; 4a ETAPA

1. Cruzamento dessa base com as bases de Silva et al. (1995) e com a base de zoneamento;

2. Análise crítica das informações;

Figura 3 - Esquema metodológico

Fonte: Elaborado pelos autores.

\subsection{1a Etapa: Aquisição e triagem de dados}

A primeira atividade dessa etapa consistiu na aquisição dos dados de ocorrências de acidentes geotécnicos registrados pela COMDEC BH entre o período de 01/01/2012 a 31/12/2015. Esse órgão dispõe de uma central telefônica que recebe chamadas de cidadãos, empresas e outras repartições públicas que, por sua vez, informam pontos do município onde ocorreram, ou podem ocorrer, acidentes ambientais. Posteriormente, os técnicos da COMDEC BH avaliam o chamado e a ocorrência do fenômeno.

Todos os registros são efetuados em uma planilha eletrônica de extensão .xlsx. A planilha de eventos geotécnicos está dividida por colunas, da seguinte maneira:

a) DATA/HORA: se refere a data e hora do chamado;

b) CÓDIGO: número de controle interno do chamado;

c) TIPO SOLICITANTE: agente que abriu o chamado;

d) TIPO LOGRADOURO: se refere ao tipo de logradouro onde ocorreu o evento;

e) NOME: nome do logradouro;

f) NÚMERO: número da propriedade;

g) COMPLEMENTO: informação complementar do endereço;

h) NDE PAVIMENTOS: quantidade de pavimentos da ocupação;

i) TIPO DE OCUPAÇÃO: distingue a ocupação entre comercial, industrial e residencial;

j) BAIRRO: Bairro da ocupação;

k) CEP: código postal da ocupação;

I) REGIONAL: regional do município em que a ocupação se localiza;

m) TIPO DE URBANIZAÇÃO: distingue a área urbana em que a ocupação se insere (pode ser uma ocupação formal ou uma vila/favela);

n) TIPO DE OCORRÊNCIA: difere "risco do acidente ocorrer" de "acidente já ocorrido" 
o) ORIGEM DA OCORRÊNCIA: distingue entre causas naturais ou humanas;

p) NATUREZA DA OCORRÊNCIA: se refere às classes dos diferentes eventos geotécnicos ocorridos no município. O parâmetro é definido pelo técnico da COMDEC BH de acordo com as descrições fornecidas pelos cidadãos comuns;

q) DESCRIÇÃO COMPLEMENTAR: informações fornecidas pelo cidadão que realizou o chamado. Útil para avaliar, ainda que superficialmente, a gravidade do acidente;

A triagem foi concebida por meio de filtros de seleção da planilha. Assim, opções foram selecionadas de acordo com o objetivo, que é o estudo da predisposição, do território de Belo Horizonte, aos riscos naturais de deslizamentos. Os filtros foram, então, aplicados:

n) TIPO DE OCORRÊNCIA: selecionada apenas a opção "Acidente Ocorrido".

o) ORIGEM DA OCORRÊNCIA: selecionada a opção "Causas Naturais".

p) NATUREZA DA OCORRÊNCIA: opção "Deslizamentos";

Após o resultado desses filtros, foi tomado o cuidado de avaliar a coluna q) DESCRIÇÃO COMPLEMENTAR e excluir dados que não apresentavam o mínimo de significância técnica para representar um fenômeno de deslizamento de encostas.

Para finalizar essa etapa, também foram avaliadas as colunas referentes a localização e data dos acidentes. Por meio de comparações foi possível excluir registros de chamados que, embora feitos por cidadãos diferentes, referiam-se ao mesmo evento. Assim, foi possível garantir que não houvesse repetição de acidentes na base de dados.

\subsection{2a Etapa: Georreferenciamento}

A segunda etapa consistiu no georreferenciamento de cada um dos registros. Isso foi feito com auxílio do software Google Earth, que permite, a partir de um mecanismo de busca, localizar um endereço em uma base online de arruamento. Para isso, foram utilizadas as colunas e) NOME (do logradouro) e f) NÚMERO (da propriedade). Uma vez localizada a propriedade, foi possível encontrar, ainda dentro do software, as coordenadas do ponto. Os pontos foram armazenados em arquivo vetorial (extensão .shp) e exportados para um SIG. 


\subsection{3a Etapa: Interpolação de dados}

No ambiente SIG o arquivo de pontos foi submetido a um processo de interpolação gerando mapas matriciais (extensão .tif). O método de interpolação escolhido foi o Método Kernel. Esse modelo permite gerar uma base cartográfica com a densidade espacial de eventos semelhantes ocorridos no território e, então, avaliar áreas de maior predisposição a tal.

Além disso, o modelo de interpolação espacial também foi escolhido pela sua simplicidade computacional. O interpolador do modelo considera apenas o agrupamento de pontos que podem, ou não, ser ponderados por algum dado tabelado e presente no arquivo vetorial (MOURA, 2012). Assim, além do interpolador indicar a concentração dos eventos, a superfície de distribuição gerada poderia responder também pela severidade desses. Neste trabalho, para a aplicação desse método, foi considerado apenas o arranjo espacial dos pontos devido à falta de informações que permitissem associar outras grandezas.

Ao final desta etapa foi gerado um arquivo vetorial a partir da matriz, o que permitiu confrontar tal resultado com os arquivos vetoriais elaborados a partir dos trabalhos de Silva et al. (1995). Para isso, o resultado da interpolação teve que passar pelo processo de Vetorização. Porém, o algoritmo tem como resultado uma matriz de distribuição contínua, inviável para isso. Como etapa intermediária, a matriz teve de passar pelo processo de Reclassificação, em que cada pixel é reclassificado conforme escala de intervalos (Tabela 1).

\begin{tabular}{cc}
\hline $\begin{array}{c}\text { Densidade espacial } \\
\left(\text { eventos } / \mathbf{k m}^{\mathbf{2}}\right)\end{array}$ & Reclassificação \\
\hline$<0,001$ & Desprezível \\
$0,001-5,000$ & Baixo \\
$5,001-10,000$ & Médio \\
$>10,000$ & Elevado \\
\hline Tabela 1- Intervalos de reclassificação \\
Fonte: Elaborado pelos autores.
\end{tabular}

\subsection{4a Etapa: Cruzamentos e Análises}

Dentro de um software de SIG a base de densidade espacial, gerada na etapa anterior, foi cruzada com a base de Predisposição ao Risco de Deslizamentos produzida, de forma quantitativa e teórica, por Silva et al. (1995). A base de densidade espacial ainda foi comparada com a base de Litologia (SILVA et al., 1995), Geomorfologia (OLIVEIRA, 2009) e Zoneamento Urbano (BELO HORIZONTE, 1996). Esses cruzamentos permitiram subsidiar 
análises da situação dos riscos geológicos em Belo Horizonte para o período e questionar os fatores que levam a concentração dos acidentes em determinadas partes do território.

Para que esses cruzamentos fossem possíveis foi necessário que todos os dados trabalhados estivessem sob um mesmo datum, projeção e escala cartográfica. Para o trabalho foram utilizados o datum WGS 1984, a projeção UTM, zona 23 Sul e a escala 1:25.000.

\section{Resultados e discussões}

\subsection{Carta de Densidade Espacial de Eventos de Deslizamentos}

A planilha eletrônica fornecida pela COMDEC BH dispunha de um total de 2414 registros no período 2012-2015. Após a aplicação dos filtros de seleção e das exclusões de registros equivocados e repetidos, foram encontrados 475 registros adequados aos critérios.

Durante a fase de georreferenciamento no software Google Earth, 21 desses registros não foram localizados. Tal fato é justificado pela não correspondência entre os nomes populares dos logradouros, informados pelos munícipes, e os nomes oficiais dos logradouros presentes, na base de dados do servidor. Também foi notado que isso se processa principalmente em locais de urbanização irregular (Tabela 2).

\begin{tabular}{c|c|c|c}
\hline \multirow{2}{*}{ Registro } & \multicolumn{2}{|c|}{ Tipo de urbanização } & \multirow{2}{*}{ Total } \\
\cline { 2 - 3 } & Formal & Irregular & \\
\hline Encontrados & 252 & 202 & 454 \\
Não encontrados & 5 & 16 & 21 \\
Total & 257 & 218 & 475 \\
\hline
\end{tabular}

Tabela 2 - Registros encontrados e não encontrados conforme tipo de urbanização Fonte: Elaborado pelos autores.

Cabe ressaltar ainda que 21 registros dentro de um grupo de 475 (cerca de 4,4\%) não representa um percentual significativo dentro do universo, nem representou a inviabilidade computacional de prosseguir com as etapas subsequentes da modelagem. Isso, pois, o intuito de uma modelagem é fazer um estudo que se aproxime da realidade, permitindo o entendimento dos fenômenos (FELGUEIRAS, 2001; MOURA, 2012; FEKETE et al., 2015). Assim, foram considerados um total de 454 pontos, que foram georreferenciados e salvos 
em um arquivo .shp. Esse arquivo, então, foi introduzido dentro de um SIG e, por meio do algoritmo do Método de Kernel, e subsequentes passos de reclassificação e vetorização, foi gerada a Carta de Densidade Espacial de Eventos de Deslizamentos (Figura 4).

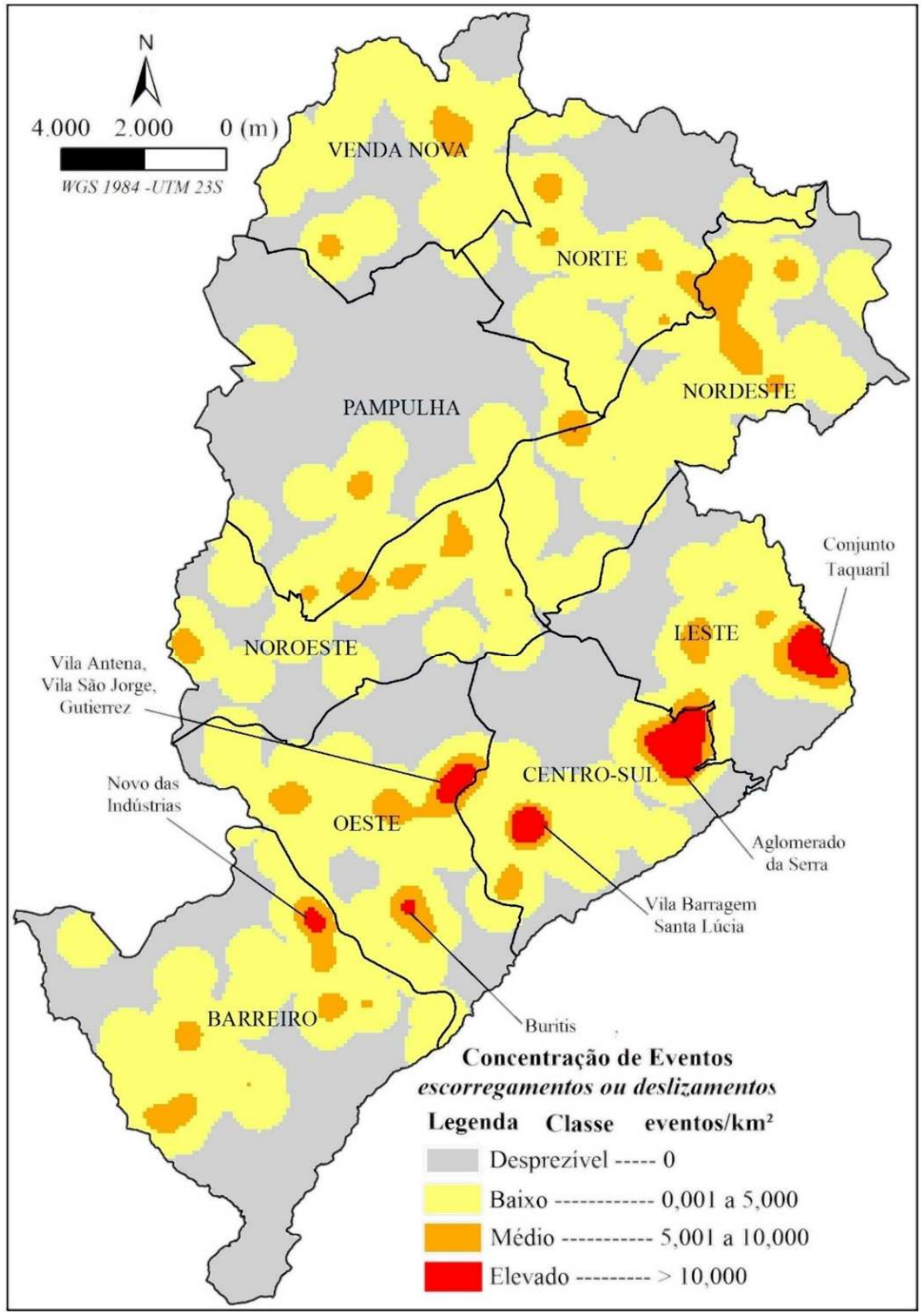

Figura 4 - Carta de Densidade Espacial de Eventos de Deslizamentos

Fonte: Elaborado pelos autores. 


\subsection{Cruzamentos}

\section{Geomorfologia}

A sobreposição (Figura 5) do mapa de densidade espacial com os modelos topográficos do município apresentados por Oliveira (2009) permitiu constatar a existência da inter-relação entre relevo e desastres geomorfológicos. As áreas onde mais ocorrem acidentes, ou seja, áreas de densidade de eventos média ou elevada ( 5,0 eventos $/ \mathrm{km}^{2}$ ) ocorrem predominantemente em compartimentos topográficos caracterizados por se localizarem ao sul e cujas vertentes possuem inclinação superior a $30 \%\left(16,7^{\circ}\right)$.

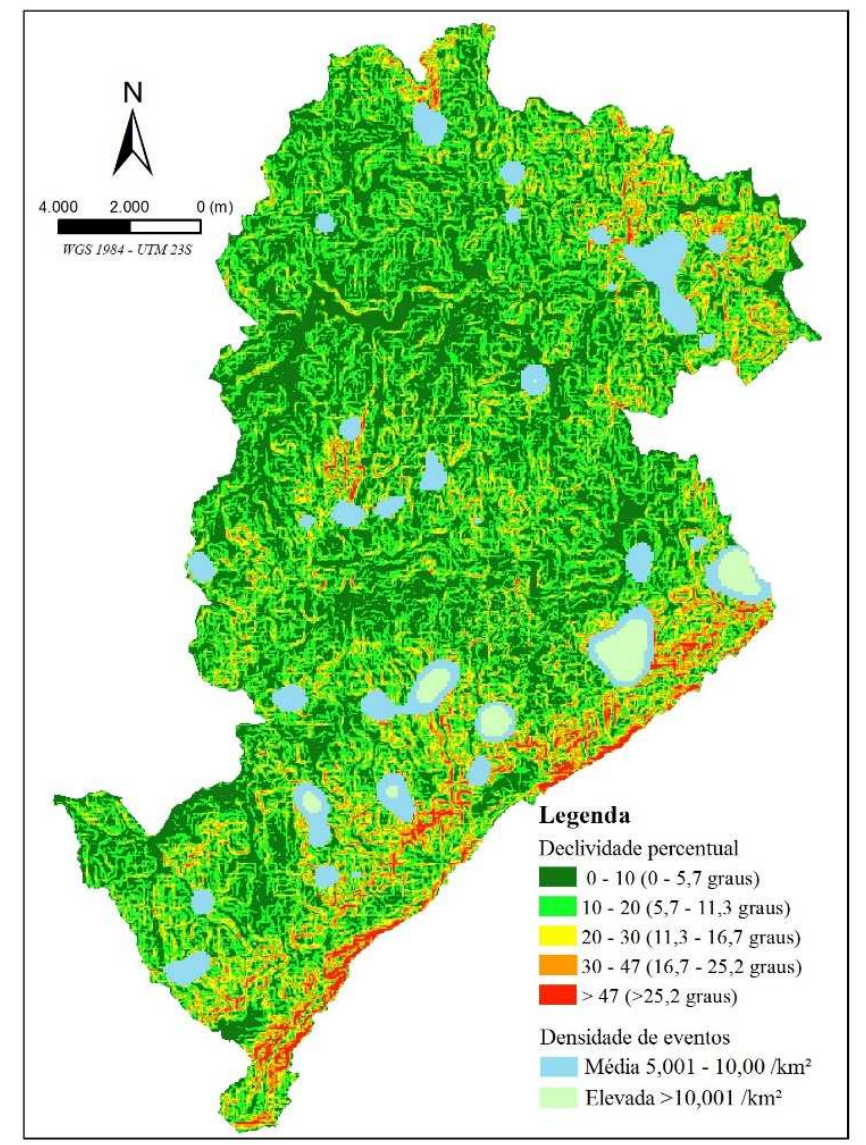

Figura 5 - Comparação entre áreas de alta densidade espacial de eventos e e a carta de declividade Fonte: Elaborado pelos autores a partir de Oliveira (2009).

* Litologia

As informações obtidas a partir do cruzamento da Carta de Densidade Espacial de Eventos com o mapa de litologia de Silva et al. (1995) foram compiladas, sendo expressas na Tabela 3, da qual se tornam evidentes alguns fatos: 
- A maior parte do território está submetida a condição de densidade desprezável $(0,0$ eventos $/ \mathrm{km}^{2}$ ) ou de densidade baixa (até 5,0 eventos $/ \mathrm{km}^{2}$ ) em áreas de geologia composta por gnaisses típicos do Complexo Belo Horizonte e vertentes de média inclinação, sendo estas áreas de grande estabilidade geotécnica.

- As regiões onde são encontrados Filitos e Xistos da Sequência Metassedimentar (Grupo Sabará), possui cerca de $57 \mathrm{~km}^{2}$ de áreas de densidade desprezível ou baixa. Contudo, é justamente sob essas formações que se localizam as áreas mais instáveis. Existem cerca $4,2 \mathrm{~km}^{2}$ de áreas de alta densidade de eventos ( $>10,0$ eventos $/ \mathrm{km}^{2}$ ) fazendo com que essa classe litológica seja a única que possua alta densidade. Essa instabilidade se deve à combinação de uma litologia de rochas friáveis com uma geomorfologia de declives acentuados.

\begin{tabular}{|c|c|c|c|c|c|c|c|c|}
\hline \multirow{3}{*}{$\begin{array}{c}\text { Densidade } \\
\text { espacial de } \\
\text { eventos }\end{array}$} & \multicolumn{8}{|c|}{ Classe litológica - área em $\mathrm{km}^{2}$} \\
\hline & \multicolumn{5}{|c|}{ Sequência Sedimentar } & \multicolumn{3}{|c|}{ Gnaisses - Complexo Belo Horizonte } \\
\hline & $\begin{array}{c}\text { Filitos e } \\
\text { Xistos (Grupo } \\
\text { Sabará) }\end{array}$ & $\begin{array}{c}\text { Filitos } \\
\text { (Formação } \\
\text { Cercadinho) }\end{array}$ & $\begin{array}{c}\text { Filitos } \\
\text { (Formação } \\
\text { Gandarela) }\end{array}$ & $\begin{array}{l}\text { Dolomitos } \\
\text { (Formação } \\
\text { Gandarela) }\end{array}$ & $\begin{array}{l}\text { Itabiritos } \\
\text { (Formação } \\
\text { Cauê) }\end{array}$ & $\begin{array}{c}\text { Espesso } \\
\text { Manto de } \\
\text { Intemperismo }\end{array}$ & Aflorantes & $\begin{array}{c}\text { Baixo Grau } \\
\text { de Evolução } \\
\text { Pedológica }\end{array}$ \\
\hline Desprezível & 11,340 & 2,582 & 14,846 & 0,037 & 2,753 & 88,744 & 1,261 & 8,547 \\
\hline Baixa & 45,748 & 4,396 & 4,646 & 0,103 & 0,272 & 92,116 & 8,777 & 22,938 \\
\hline Média & 7,673 & 0,390 & 0,022 & 0,000 & 0,000 & 4,277 & 1,340 & 4,405 \\
\hline Elevada & 4,243 & 0,015 & 0,000 & 0,000 & 0,000 & 0,008 & 0,053 & 0,053 \\
\hline
\end{tabular}

Tabela 3 - Densidade espacial de eventos por classe litológica Fonte: Elaborado pelos autores.

\section{Predisposição ao Risco}

A síntese dos trabalhos de Silva et al. (1995) foram as cartas de predisposição aos riscos geoambientais, dentre as quais encontra-se a Carta de Predisposição ao Risco de Deslizamentos de Encostas, elaborada de forma teórica. A Figura 6 mostra a comparação entre os estudos teóricos desses autores (Figura 6-A) com o mapa de densidade espacial de eventos (Figura 6-B) produzido nesta pesquisa de forma empírica. 


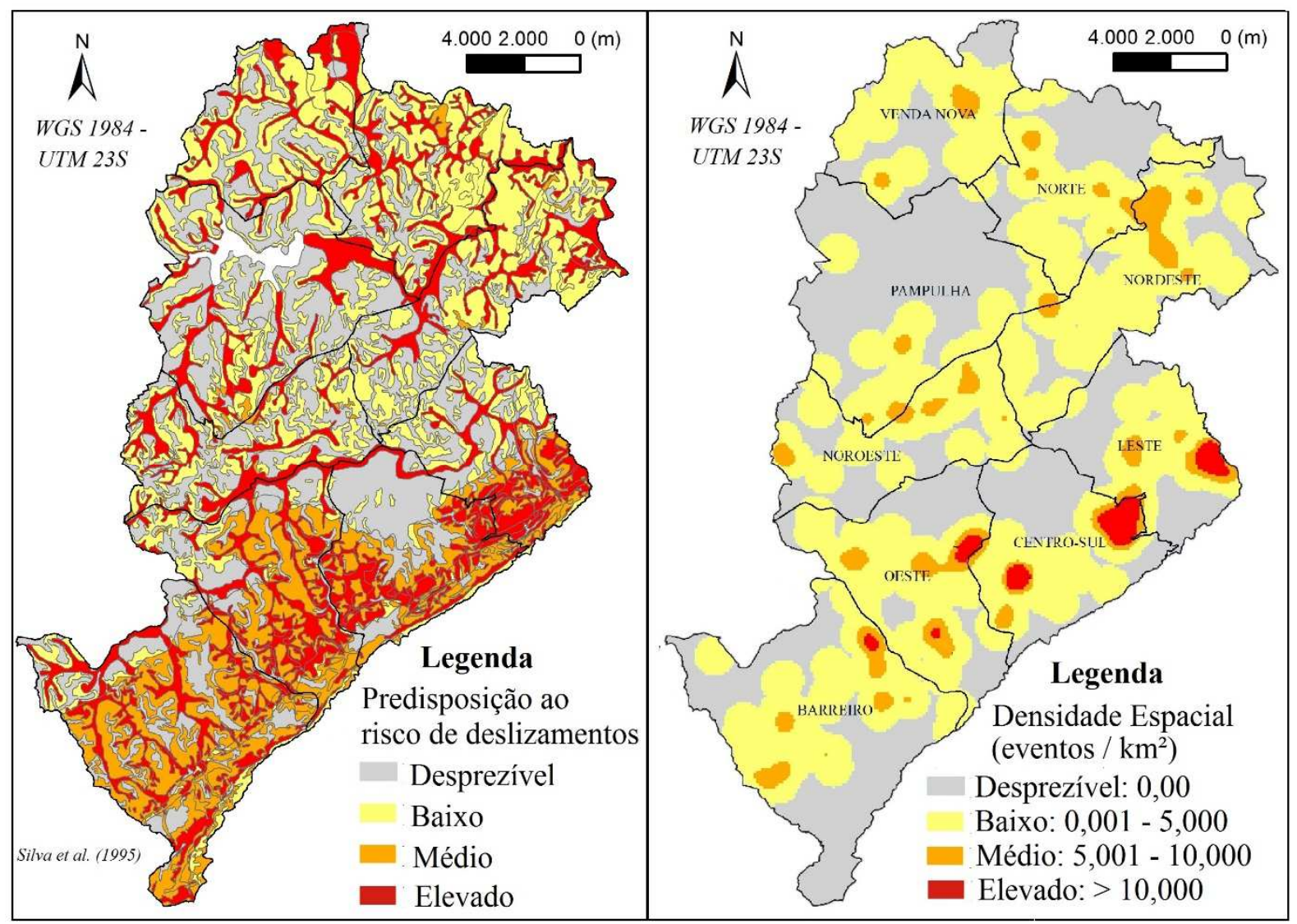

Figura 6 - Comparação da carta de Predisposição ao Risco de Deslizamentos (SILVA el al.,1995) com a Carta de Densidade Espacial de Eventos Fonte: Elaborado pelos autores.

$\mathrm{Na}$ tentativa de quantificar as divergências existentes entre as cartas foi construída a Tabela 4. Essa matriz expressa os percentuais de cada classe, da Carta de Predisposição ao Risco de Deslizamentos, sobreposta às classes da Carta de Densidade Espacial de Eventos. A diagonal da matriz expressa os percentuais de áreas da carta de predisposição que foram igualmente classificadas na carta de densidade espacial, enquanto os dados de fora dessa diagonal expressam a incompatibilidade entre as duas classificações.

A leitura da tabela evidencia alguns fatos que podem ser interessantes para o planejamento de ações de prevenção. Do total de áreas classificadas com predisposição alta na carta de Silva et al. (1995), apenas 3,58\% estão em regiões de incidência concentrada desse tipo de fenômeno. Já para predisposição média, apenas $8,44 \%$ do total de áreas estão em regiões com concentração de eventos também pode ser considerada média. 


\begin{tabular}{c|c|c|c|c}
\hline \multirow{2}{*}{$\begin{array}{c}\text { Classe de } \\
\text { Densidade } \\
\text { Espacial de } \\
\text { Eventos }\end{array}$} & \multicolumn{4}{|c}{$\begin{array}{c}\text { Percentual (\%) de sobreposição de áreas com Predisposição ao } \\
\text { Risco em relação às classes de Densidade Espacial de Eventos }\end{array}$} \\
\cline { 2 - 5 } & $\begin{array}{c}\text { Predisposição } \\
\text { Desprezível }\end{array}$ & $\begin{array}{c}\text { Predisposição } \\
\text { Baixa }\end{array}$ & $\begin{array}{c}\text { Predisposição } \\
\text { Média }\end{array}$ & $\begin{array}{c}\text { Predisposição } \\
\text { Alta }\end{array}$ \\
\hline Desprezível & $\mathbf{4 6 , 7 3}$ & 36,09 & 32,72 & 36,89 \\
Baixo & 50,37 & $\mathbf{5 7 , 6 8}$ & 56,56 & 53,11 \\
Médio & 2,57 & 6,22 & $\mathbf{8 , 4 4}$ & 6,42 \\
Alto & 0,33 & 0,01 & 2,29 & $\mathbf{3 , 5 8}$ \\
\hline TOTAL & 100,0 & 100,0 & 100,0 & 100,0 \\
\hline
\end{tabular}

Tabela 4 - Percentual de sobreposição entre as classes de Predisposição ao Risco e as classes de Densidade Espacial de Eventos Fonte: Elaborado pelos autores.

\section{* Zoneamento Urbano}

Com a carta de densidade para o período 2012-2015, foi possível identificar seis áreas em que ocorrem intensas concentrações de casos do fenômeno em questão. Das seis áreas em que ocorre concentração de deslizamentos, cinco abrangem vilas, favelas e conjuntos habitacionais de baixa renda. Esse fato reafirma que o processo de urbanização sem planejamento prévio ocorreu em áreas de elevada instabilidade geomorfológica.

Contudo, dentro dessas áreas também foram identificados bairros de classe média e bairros nobres. Cabe ressaltar ainda que, de acordo como a legislação municipal, esses bairros estão em zonas onde existem padrões construtivos que, em teoria, tentam minimizar o impacto ambiental proveniente da urbanização com o objetivo de não expor ainda mais a população residente a eventos desastrosos.

\section{Conclusões e recomendações}

Os resultados aqui apresentados corroboram o que é afirmado por autores como Abreu (2007), Tominaga (2007), Marcelino (2008), Franca (2009), Parizzi et al. (2010), Paolucci (2012) e outros tantos. Eles demonstraram a interdependência direta entre os fatores do meio físico e os desastres naturais. Em Belo Horizonte, especificamente, os acidentes geomorfológicos possuem relação com o relevo e com a litologia. 
Apesar desta investigação não ter avaliado fatores climáticos dentro do escopo da modelagem proposta, foi notado que a maioria dos eventos ocorreram nos meses de dezembro e janeiro, época de verão no Hemisfério Sul. Esses meses são marcados por fortes chuvas no município, o que intensifica a ação de processos erosivos, tal como é discutido por Alcantara-Ayala \& Goudie (2011). Logo, é recomendado o maior aprofundamento sobre a perspectiva climática, seja para aprimorar os resultados da Carta de Densidade Espacial, seja para aumentar a eficácia dos mecanismos de GRD promovidos pela COMDEC BH.

No que diz respeito à topografia, áreas acima de 850 metros de altitude e com declividades acima de $30 \%$ são as mais susceptíveis a deslizamentos de encostas. Em relação à litologia, maior predisposição ocorre em regiões de filitos e xistos da porção sul do território. Fato que requer maior atenção quando é analisado o processo histórico de ocupação e se observa que foi onde a cidade teve início e se urbanizou mais intensamente.

Este trabalho teve como enfoque averiguar os eventos geomorfológicos de causa natural, contudo não deve ser desprezada a componente antrópica que também influencia esses eventos, pois ela existe e é atuante. A análise dos dados da COMDEC BH evidenciou que, em termos absolutos, a maioria dos eventos ocorrem dentro da cidade formal e não dentro das favelas como o senso comum pode levar a pensar. Entretanto, é justamente nesses bairros onde ocorre a maior concentração desses fenômenos por unidade de área.

Esses espaços se tornam extremamente complexos para a GRD e para o planejamento da cidade (NOGUEIRA, 2002; FÉLIX 2016). Isso porque, em primeiro lugar, historicamente a população de renda mais baixa ocupou áreas cujas características físicas são inapropriadas ao adensamento urbano. Em segundo lugar, o planejamento deficiente dessas áreas levou a uma urbanização desordenada e com restrições viárias e de saneamento, o que, por conseguinte, dificulta a implementação de medidas de controle dos riscos e potencializa os fenômenos naturais adversos.

Restrições a urbanização devem ser concebidas a partir de um planejamento eficiente e que considere os riscos ambientais nas políticas de urbanização. Afinal, eventos de instabilidade geomorfológica ocorrem tanto em áreas de vilas e favelas como em áreas formais.

Nessa lógica, é reafirmada a ideia de UN (2004), García (2007) e Fekete et al. (2015) que a elaboração de planos de gerenciamento de desastres deve passar impreterivelmente pelo 
conhecimento do território. Porém, para gerenciar riscos o estudo do território não deve se pautar apenas sobre as suas condicionantes fisiográficas, mas também sobre suas características socioeconômicas, políticas, culturais e urbanísticas. Afinal, a relação que o ser humano exerce com o meio a partir do seu modo de se estabelecer sobre o solo pode intensificar em força, tamanho e frequência os desastres ambientais.

Conceitualmente o estudo da predisposição indica os locais que devem receber atenção especial para que desastres de ordem natural não ocorram, já a carta de densidade indica a concentração de eventos ocorridos. Logo, a comparação entre esses mapas, para um período determinado, pode ser utilizada como uma forma de avaliar a relação existente entre o risco potencial e o risco efetivo de uma região.

Daí, quando ocorre de uma região possuir alta predisposição e baixa densidade, ou, por outro lado, se ocorrem eventos em locais onde a predisposição é baixa, cabe ao analista se aprofundar sobre o estudo da localidade, pois algum processo pode estar se desenvolvendo ali. Esses processos podem ocorrer devido a uma anomalia geodinâmica ou em decorrência da ação antrópica sobre o meio. O ser humano pode estar interferindo positivamente no sentido de conter os riscos com ações preventivas, ou, mesmo de forma negativa, aumentando a frequência e intensidade dos eventos a partir do uso inadequado do solo.

Assim, a incongruência entre a carta de predisposição ao risco Silva et al. (1995) e o mapa de densidade espacial ressalta, a existência de processos ambientais no território de Belo Horizonte. Esses processos devem ser particularizados e melhor estudados a fim de otimizar o gerenciamento dos riscos, a prevenção de desastres e o aumento da resiliência.

Cabe ressaltar ainda que a metodologia utilizada pode ser melhorada em diversos pontos. Por exemplo, a escolha do modelo de densidade de kernel levou em consideração apenas o número de eventos ocorridos, não considerando a intensidade de cada evento. Essa segunda variante pode ser acrescida ao modelo gerando resultados mais precisos, porém devido à falta de dados não foi possível realizar essa ação.

Outro ponto que contribui para a redução da precisão do mapa de densidade é que foram considerados apenas os casos registrados pela COMDEC BH a partir do relato de cidadãos e outros colaboradores. Isso desconsidera eventuais acidentes geológicos que podem ter 
ocorrido, porém que não foram informados ao órgão de defesa civil e, assim, não puderam influenciar nos resultados finais.

Embora seja ainda possível aumentar a precisão dos mapas, tal como estão já são de grande relevância para o GRD em Belo Horizonte. As análises e cartografias aqui produzidas podem ser úteis para aumentar a eficiência dos sistemas de reconhecimento de regiões altamente susceptíveis e de grande vulnerabilidade. Esses mapas são ferramentas de gestão territorial que podem contribuir para direcionar, de forma mais eficiente, recursos apropriados para o enfrentamento dos riscos.

\section{Referências bibliográficas}

ABREU, Uriel Arcanjo Vieira. Riscos naturais no ordenamento do território: aplicação ao município de Câmara de Lobos. Dissertação de Mestrado, Universidade de Coimbra, Coimbra, 2007.

ALCÁNTARA-AYALA, Irasema; GOUDIE, Andrew. Geomorphological Hazards and Disaster Prevention. 1a ed.. Cambridge: Cambridge University Press, 2011. ISBN 978-0511807527

BELO HORIZONTE (Prefeitura Municipal), 2007. GESTÃO DO RISCO GEOLÓGICO EM BELO HORIZONTE - MG. Belo Horizonte. URBEL.

CAMPOS, Luciane. Proposta de reanálise do risco geológico-geotécnico de escorregamentos em Belo Horizonte, MG. Dissertação de Mestrado, Universidade Federal de Minas Gerais, Belo Horizonte, 2011.

FEKETE, Alexander; TZAVELLA, Katerina; ARMAS, Iuliana; BINNER, Jane; GARSCHAGEN, Matthias; GIUPPONI, Carlo; MOJTAHED, Vahid; PETTITA, Marcello; SCHNEIDERBAUER, Stefan; SERRE, Damien. Critical Data Source; Tool or Even Infrastructure? Challenges of Geographic Information Systems and Remote Sensing for Disaster Risk Governance. ISPRS -International Journal of Geo-Information, September 2015, vol. 4, n 4, p.1848-1869. [Viewed 27 September 2016]. Available from: doi: //dx.doi.org/10.3390/ijgi4041848>

FELGUEIRAS, Carlos. Modelagem Ambiental Com Tratamento De Incertezas Em Sistemas De Informação Geográfica. Tese de Doutorado, Instituto Nacional de Pesquisas Espaciais, São José dos Campos, 2001.

FÉLIX, Amanda. A gestão do risco de desastres: um olhar para os registros de ocorrências da defesa civil do município do Rio de Janeiro. Dissertação de Mestrado, Universidade Federal Fluminense, Niterói, 2016.

GARCÍA, José Luis González (Org.), 2007. Implicaciones económicas y sociales de los riesgos naturales. 1a Ed.. Madrid: Elece. 2007. ISBN 978-84-690-9276-7.

LEI MUNICIPAL no 7.165/1996. Institui o Plano Diretor Municipal de Belo Horizonte. Belo Horizonte, 27-081996. Diário Oficial do Município, 1-48.

LEI MUNICIPAL no 7.166/1996. Estabelece normas e condições para parcelamento, ocupação e uso do solo urbano no município. Belo Horizonte, 27-08-1996. Diário Oficial do Município, 1-91.

MARCELINO, Emerson Vieira, 2008. Desastres Naturais e Geotecnologias: Conceitos Básicos. Santa Maria: INPE (Instituto Nacional de Pesquisas Espaciais). INPE-15208-PUD/193.

MOURA, Ana Clara Mourão. Geoprocessamento na Gestão e Planejamento Urbano. 3. ed.. Belo Horizonte: da Autora, 2014. ISBN: 9788571933583 
MOURA, Ana Clara Mourão, 2012. A escolha de interpoladores e recursos de visualização na estruturação de bases de dados para produção de informações espaciais apoiadas por geoprocessamento. Belo Horizonte: Laboratório de Geoprocessamento da Escola de Arquitetura da UFMG.

MPO (Ministério do Planejamento e Orçamento - Secretaria de Defesa Civil), 1998. GLOSSÁRIO DE DEFESA CIVIL: ESTUDOS DE RISCOS E MEDICINA DE DESASTRES. 2. ed. Brasília: Imprensa Nacional.

NOGUEIRA, Fernando Rocha. Gerenciamento de riscos ambientais associados a escorregamentos: Contribuição às políticas públicas municipais para áreas de ocupação subnormal. Tese de Doutorado, Universidade Estadual Paulista, Rio Claro, 2002.

OLIVEIRA, Marcelo Tuler de. Estudo de movimentos de massa gravitacionais no município de Belo Horizonte, MG. Tese de Doutorado, Universidade Federal de Viçosa, Viçosa, 2009.

PAOLUCCl, Cindy. Risco hidrometeorológico no município de Belo Horizonte: eficiências e deficiências desde 1990. Dissertação de Mestrado, Universidade Federal de Minas Gerais, Belo Horizonte, 2012.

PARIZZI, Maria; SEBASTIÃO, Cristiane; VIANA, Cláudia; PFLUEGER, Marcelo; CAMPOS, Luciane; CAJAZEIRO, Joana Maria; TOMICH, Rodolfo; GUIMARÃES, Roberta; ABREU, Magda; SOBREIRA, Frederico; REIS, Ruibran. Correlações entre chuvas e movimentos de massa no município de Belo Horizonte, MG. GEOgrafias, Dezembro 2010, vol. 6, no 2, p. 49-68. ISSN 2237-549X.

REIS, Patrícia Elizama. O escoamento superficial como condicionante de inundação em Belo Horizonte, MG. Dissertação de Mestrado, Universidade Federal de Minas Gerais, Belo Horizonte, 2011.

SILVA, A. B., CARVALHO E.T., FANTINEL L.M., ROMANO A.W, VIANA C.S., 1995. Estudos Geológicos, Hidrogeológicos, Geotécnicos e Geoambientais Integrados no Município de Belo Horizonte. Belo Horizonte: Convênio PBH/FUNDEP.

STARLING, Paula Miller. O risco geológico como justificativa para remoções forçadas no Aglomerado Santa Lúcia e na Vila Bandeirantes em Belo Horizonte. Dissertação de Mestrado, Universidade Federal de Minas Gerais, Belo Horizonte, 2015.

TOMINAGA, Lídia Keiko. Avaliação de metodologias de análise de risco a escorregamentos: aplicação de um ensaio em Ubatuba, SP. Tese de Doutorado, Universidade de São Paulo, São Paulo, 2007.

UMBELINO, Glauco José de Matos. Proposta metodológica para avaliação da população residente em áreas de risco ambiental: o caso da bacia hidrográfica do Córrego do Onça/MG. Dissertação de Mestrado, Universidade Federal de Minas Gerais, Belo Horizonte, 2006.

UN (UNITED NATIONS), 2004. Living with risk: A global review of disaster reduction initiatives. Geneva: ISDR (Inter-agency Secretariat International Strategy for Disaster Reduction).

UN (UNITED NATIONS), 2010. Land and Natural Disasters: Guidance for Practitioners. Nairobi: UN-Habitat Agency. 